\title{
'Mad cow' politics tries to corral science
}

Paris. Science was this week once again called to the aid of politicians in Europe's 'mad cow' crisis, when the British government asked the European Commission to revise a previous agreement under which Britain would reduce the incidence of bovine spongiform encephalopathy (BSE) by culling 127,000 cattle.

The UK government has been reviewing the cull following the publication of an analysis suggesting that the epidemic phase of BSE would end around 2001 without any culling, and that, given the aetiology of the disease and uncertainty about which cattle are infected, its decline would not be greatly accelerated by any culling policy short of the slaughter of around a quarter of the 10 million cattle in the national herd.

But the interpretation of this analysis, which also puts estimated numbers on the level of infected cattle remaining in British herds, has also become a centre of controversy, with others contesting the claim that it undermines demands for a broad cull.

Speaking at a meeting of European Union (EU) farm ministers on Monday (16 September), Douglas Hogg, the UK agriculture minister, said that the paper concerned showed that "BSE will in any event die out in 2000 or 2001 ", and that there was no culling policy that "would make a substantial difference to the rate of decline".

The cull was originally agreed to by John Major, the prime minister, at the European Union summit in Florence in June, as the price to pay for an eventual lifting of the EU ban on the export of UK beef products. But Major needs parliamentary approval before the cull can go ahead, and this looks increasingly unlikely, given growing opposition among Tory members of Parliament.

There is also uncertainty about how the opposition Labour party will vote (opposing the cull would also win votes among farmers). With the prospect of an immediate lifting of the ban seeming increasingly remote, Major seems to be gambling on satisfying domestic interests at the risk of inflaming other EU governments, by demanding that the cull be reduced or abandoned.

The government is relying on the results of a study published by Roy Anderson, professor of zoology at the University of Oxford, and both academic colleagues and scientists working for the UK Ministry of Agriculture Fisheries and Food (MAFF). They used sophisticated modelling techniques and previously confidential MAFF statistics to analyse the transmission dynamics and epidemiology of BSE (see Nature 382, 787; 1996). They also compared the 'efficiency' of 14 different culling strategies, defined by the number of cases they eliminate for the total number of cattle culled.

But the European Commission disputes that the results undermine arguments in favour of the planned cull. The paper's estimates of the "efficiency" of various culling strategies - in terms of how many cattle need to be killed to get rid of BSE cases are of no interest to the commission, says Gerard Kiely, a spokesman for Franz Fischler, the agriculture commissioner. "Whether it is 10,000 or 2 million cattle is irrelevant to us; what is relevant is reducing BSE [cases] as fast as possible," he says.

In contrast, Kiely argues that new evidence of maternal transmission of BSE - which, as previously announced, has been submitted to Nature - could, in fact, require an enlargement of the cull. The

\section{IMAGE UNAVAILABLE FOR COPYRIGHT REASONS}

Mulling the cull: Hogg is trying to persuade Europe that a cull will make little difference to the rate of decline of BSE.

commission is open to reviewing the culling policy to take into account such data, he says, as it would allow "taking out more cases of BSE".

Like other critics, Kiely also points out that interpretations of the Anderson paper other than that of the British government are possible, and that the evaluation of the various culling strategies could similarly justify not a reduction but an extension of the planned cull. According to the Anderson paper, the agreed cull of 127,000 cattle would eliminate 1,580 cases of BSE. But by adding a maternally targeted policy and killing 150,000 cattle, 2,380 cases would be eliminated. "I think many member states would say that is the one we need," says Kiely.

Some scientists are also concerned that the British government has selected an interpretation of the paper that suits its political needs - reinforcing the view that governments tend to accept scientific advice when it suits them and to reject it when it does not.

Mark Savey, a leading French epidemiologist on BSE, and a member of the BSE working group of the European Commission's scientific veterinary committee, also argues that the rapid interpretation given to the findings raises the wider problem of what he claims is insufficient discussion of research results in the BSE crisis.

"Non-scientists think that when a paper is published in a prestigious journal, it is the indisputable single truth - that the matter is settled," says Savey. "But publication is only the first step; there is no paper in the BSE crisis that will close the discussion, and we will be discussing this disease for another decade."

In support of his arguments, Savey points out that much of the current literature focuses on the 'epidemic phase' of the disease. "It is a very British way of looking at things," he says. The British "say that BSE will be finished as an epidemic in 2001. What they don't say is that the disease will not have disappeared completely."

The scientific issue is to know whether the disease will remain sporadic, and how will this be handled, he says, pointing out

that low levels of the disease in France has been enough to panic consumers. In a sporadic phase, BSE might evolve to find other routes of transmission, he warns, adding that the scientific community needs to "start thinking now" about these problems.

Savey also argues that, whereas the Anderson paper is "absolutely superb", the scientific aspects of the cull are merely one consideration. While scientific advice may influence culling policy, it would be simplistic to believe it should determine it, he says, arguing that this can only be done by also taking into account political, economic and other factors.

Certainly science, up to now, has had little to do with the decision to cull UK cattle. The cull was agreed by EU member states largely as a means of restoring public confidence in beef. But from the outset it has been opposed as lacking scientific justification by many scientific advisory bodies, including the British government's Spongiform Encephalopathy Advisory Committee (SEAC) and the World Organization for Animal Health.

Some British researchers argue, however, that the confirmation that any cull short of a massacre would not eradicate BSE any faster than doing nothing only lends weight to existing scientific criticism of the cull. "I suppose that is what the government is looking at, and I think the science supports it," says one of the paper's authors.

The epidemic should be allowed to die out naturally, given that precautions have been taken by abattoirs to prevent infected animals entering the food chain, says Ray Bradley, a MAFF scientist who is a member of SEAC and also chairman of the BSE working group of the European Commission's scientific veterinary committee. "The cull has no scientific basis," he says baldly. "It is only there to appease the other member states of EU." Declan Butler 